
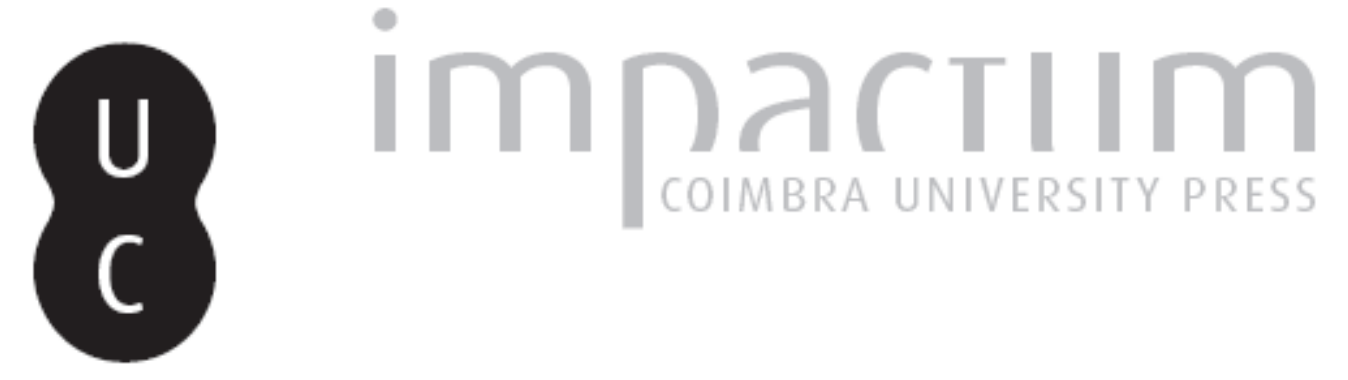

\title{
Valorização turística da ilha da Morraceira (Município da Figueira da Foz): novas utilizações do potencial endógeno do estuario do Mondego
}

\author{
Autor(es): $\quad$ Cordeiro, A. M. Rochette; Paredes, Liliana Catarina
}

Publicado por: $\begin{aligned} & \text { Faculdade de Letras da Universidade de Coimbra, Departamento de } \\ & \text { Geografia }\end{aligned}$

URL

persistente:

URl:http://hdl.handle.net/10316.2/30223

DOI:

DOI:http://dx.doi.org/10.14195/0871-1623_32_18

Accessed : $\quad$ 26-Apr-2023 15:01:17

A navegação consulta e descarregamento dos títulos inseridos nas Bibliotecas Digitais UC Digitalis, UC Pombalina e UC Impactum, pressupõem a aceitação plena e sem reservas dos Termos e Condições de Uso destas Bibliotecas Digitais, disponíveis em https://digitalis.uc.pt/pt-pt/termos.

Conforme exposto nos referidos Termos e Condições de Uso, o descarregamento de títulos de acesso restrito requer uma licença válida de autorização devendo o utilizador aceder ao(s) documento(s) a partir de um endereço de IP da instituição detentora da supramencionada licença.

Ao utilizador é apenas permitido o descarregamento para uso pessoal, pelo que o emprego do(s) título(s) descarregado(s) para outro fim, designadamente comercial, carece de autorização do respetivo autor ou editor da obra.

Na medida em que todas as obras da UC Digitalis se encontram protegidas pelo Código do Direito de Autor e Direitos Conexos e demais legislação aplicável, toda a cópia, parcial ou total, deste documento, nos casos em que é legalmente admitida, deverá conter ou fazer-se acompanhar por este aviso.

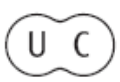




\title{
Valorização turística da ilha da Morraceira (Município da Figueira da Foz): novas utilizações do potencial endógeno do estuário do Mondego
}

\author{
A. M. Rochette Cordeiro \\ Departamento de Geografia e Centro de Estudos de Geografia e Ordenamento do Território (CEGOT). Faculdade de Letras da Universidade de Coimbra. \\ rochettecordeiro@fl.uc.pt
}

\section{Liliana Catarina Paredes}

Bolseira de Investigação. Faculdade de Letras da Universidade de Coimbra.

lilianarparedes@gmail.com

\section{Resumo:}

No território municipal da Figueira da Foz, a riqueza excecional dos recursos naturais, associados à extensa linha de costa, o estuário, as lagoas interdunares e mesmo os cursos de água, justificaram a necessidade de elaboração de um plano estratégico no âmbito da implementação e desenvolvimento de atividades turísticas sustentáveis que constituam uma alternativa ao "clássico" turismo sol/mar.

O objetivo final do "Plano de Valorização Turística da Ilha da Morraceira" passa pela implementação de uma estratégia concertada e integrada que respeite os valores ambientais intrínsecos, promovendo a sensibilização ambiental dos visitantes, bem como a divulgação dos principais aspetos culturais e dos valores locais associados à salicultura e à observação da avifauna (birdwatching).

Palavras-chave: Recursos Naturais. Salicultura. Ecoturismo. Turismo Sustentável. Estuário do Mondego.

\section{Resumé:}

Valorisation Touristique de l'île de Morraceira (Municipalité de Figueira da Foz): nouvelles utilisations du potentiel endogène de l'estuaire du Mondego

Sur le territoire municipal de Figueira da Foz, la richesse exceptionnelle des ressources naturelles, associée à un grand littoral, l'estuaire, les lagunes interdunaire et même les cours d'eau, ont justifié la nécessité d'élaborer un plan stratégique au sein de l'implantation et du développement d'activités touristiques durables qui constituent une alternative au «classique» tourisme soleil/mer.

L'objectif final du «Plan de Valorisation Touristique de l'île de Morraceira» passe par la mise en œuvre d'une stratégie concertée et intégrée, qui respecte les valeurs environnementales intrinsèques, promouvant la sensibilisation à l'environnement des visiteurs, ainsi que la divulgation des principaux aspects culturels et les valeurs locales associées à la saliculture et à l'observation de l'avifaune (birdwtaching).

Mots-clés: Ressources Naturelles. Saliculture. Ecotourisme. Tourisme Durable. Estuaire du Mondego.

\section{Abstract}

Touristic Valuation of the Morraceira Island (Figueira da Foz): new usages of the endogenous potential in the Mondego Estuary

In the municipal territory of the Figueira da Foz, the exceptional wealth of the natural resources, associated to the extensive shoreline, the estuary, the lagoons between the dunes and the water courses, brought up the need to make a strategic plan for the implementation and development of sustainable tourist activities, which will bring up a alternative to "the classic" sun/sea tourism.

The "Touristic Valuation Plan of the Morraceira Island" main goal was to implement a mild and integrated strategy that respects the intrinsic environmental values, promoting the visitors' ecological education, as well as the spreading of the main local culture and of the salt making and birdwatching.

Keywords: Natural Resources. Salt Making Industry. Ecotourism. Sustainable Tourism. Mondego's estuary. 


\section{Introdução}

O posicionamento geográfico de Portugal Continental tem vindo a ditar a necessidade absoluta de definição de estratégias, nas quais se encontrem preconizadas medidas de proteção e valorização dos recursos endógenos associados ao mar e cujo objetivo central deverá passar pela construção de uma economia do mar que potencie a qualidade de vida e bem-estar dos cidadãos, em particular os que vivem e desenvolvem as suas atividades nos setores do litoral.

Esta estratégia deverá vir a ser o resultado de uma articulação de várias políticas, das quais se destacam, neste particular, a "Estratégia Nacional de Desenvolvimento Sustentável", a "Estratégia Nacional de Conservação da Natureza e Biodiversidade", a "Estratégia de Gestão Integrada da Zona Costeira", o "Plano Estratégico Nacional de Turismo" (PENT) e o "Programa Nacional de Turismo de Natureza" (PNTN).

No caso particular da Figueira da Foz, o objetivo primordial passa assim pela articulação de diversas áreas, tais como as do ambiente, do ordenamento do território, do desporto, do património cultural, da saúde, entre outras, no sentido de sensibilizar a sociedade civil para a necessidade de promoção da Figueira da Foz como destino turístico diversificado e de qualidade (PARedes, 2008; Cordeiro, coord, 2012).

Foi neste contexto e sob a chancela do conceito desenvolvimento sustentável que surgiu o "Plano de Valorização Turística da Ilha da Morraceira", cujos eixos estratégicos passam pelas áreas temáticas da educação, da sensibilização ambiental, da cultura e mesmo do desporto, assumidas como atividades de turismo e lazer em espaço natural. Este plano deve ser entendido como uma das muitas peças que, presentemente, se encontram a ser trabalhadas no âmbito do "Plano Estratégico de Desenvolvimento" do concelho da Figueira da Foz (Cordeiro, coord., 2012).

O Estuário do Mondego, território caracterizado por baixas altitudes e de formação muito recente, integra diferentes setores, dos quais se destaca, pela sua extensão e pela sua riqueza, a Ilha da Morraceira.

As particularidades culturais e, em especial, as naturais, levaram mesmo a que fosse classificada como sítio RAMSAR. A sua riqueza florística e faunística, que tem vindo a ser apresentada em diferentes trabalhos científicos (MARQues, 2005; RIBEIRo, 2006; Cruz et al, 2011), bem como a atividade secular de salicultura, ditam que este espaço deva ser entendido como estratégico para o tão desejado desenvolvimento sustentado do concelho. Porém, este setor encontra-se, desde há muito, aparentemente esquecido pela maioria dos cidadãos do próprio concelho, requerendo por esse facto um projeto urgente de valorização.

Neste contexto, e com base nos eixos estratégicos que foram definidos no PENT para o Centro de Portugal - Touring Cultural e Paisagístico, Saúde e Bem-estar, Gastronomia e Vinhos e Turismo Naútico - pretende-se a valorização e promoção das características da Itha da Morraceira e restantes setores do Salgado da Figueira da Foz, numa ótica de afirmação como espaço turístico de excelência, mas assumindose numa lógica integrada de um projeto mais amplo que é o "Plano Estratégico de Desenvolvimento da Figueira da Foz". A ilha deve mesmo vir a constituir-se como uma área de recuperação, conservação e valorização do património natural e cultural, de modo a viabilizar e diversificar a oferta turística (no sentido da desejada complementaridade ao turismo de sol/mar que nas últimas décadas tem constituído a imagem do concelho) contribuindo, assim, para um desenvolvimento sustentável do território.

A metodologia utilizada teve por base, não só um intenso trabalho de campo, como também uma ampla pesquisa bibliográfica no sentido de caracterização e identificação dos aspetos sociais, económicos, culturais e patrimoniais da llha e dos setores adjacentes. Aqui destaca-se a análise do "Plano Director da Itha da Morraceira" (MARQUES, 2005), documento no qual foram definidas algumas das linhas mestras de intervenção para este território, bem como as potenciais ligações entre os diferentes setores de desenvolvimento que um território como a Ilha da Morraceira pode proporcionar. Num contexto como aquele que foi encontrado, as novas propostas foram baseadas no incremento das atividades associadas ao ecoturismo e no aumento do número de turistas/visitantes, assim como na procura de novos caminhos para o desenvolvimento das atividades tradicionais.

\section{A Ilha da Morraceira: os recursos naturais e as atividades económicas}

Desenvolvendo-se por uma área de cerca de 35 $\mathrm{Km}^{2}$, o estuário do Mondego, e em particular o seu setor distal, assume-se como uma unidade geográfica central no território concelhio da Figueira da Foz, separando fisicamente os setores sul e norte (Figura 1). Apresentando vastas extensões de sapais e caniçais, bem como de salinas, aquaculturas/pisciculturas 
e arrozais (Fotos 1 e 2), o estuário desenvolve-se pelos territórios das freguesias de Lavos, São Pedro, Vila Verde e São Julião.

A ilha da Morraceira propriamente dita apresenta uma área aproximada de 600 hectares, num total de $7 \mathrm{~km}$ de comprimento, encontrando-se individualizada por dois braços fluviais: o braço Norte mais profundo e mais dinâmico (subsistema do Mondego, com profundidades máximas de 10 metros), e o braço Sul (subsistema do Pranto) menos dinâmico e assoreado, nos setores mais a montante (MARQues, 2005; Cordeiro, coord, 2012).

A ilha caracteriza-se por apresentar declives baixos, com grande predomínio de sapal em toda a área, características resultantes de uma deposição de sedimentos aluvionares (areias e lodos), em especial na zona mais a jusante do estuário, sedimentação que esteve na génese da própria ilha.

Em termos climáticos, o setor onde se localiza o estuário do Mondego (e todo o vasto território do Baixo Mondego) apresenta um clima mediterrâneo de feição atlântica, com verões mais ou menos quentes e secos e com Invernos suaves e pluviosos. Estas características associam-se, inequivocamente à grande riqueza em termos de fauna e flora que a ilha (e restantes áreas do estuário) apresenta ao longo do ano. As mesmas características morfológicas e climáticas são também a razão de ser de, historicamente, a exploração do sal na Itha da Morraceira e, genericamente no Estuário do Mondego ter sido uma das principais atividades económicas existentes no território municipal, na medida em que este local apresentava características únicas (mesmo em termos europeus) das quais resultavam uma produção de sal com determinadas especificidades, difíceis de encontrar nas restantes regiões salineiras portuguesas (RibeIRo, 2005; 2006).

Sendo um local de grande biodiversidade, o Estuário do Mondego e a llha da Morraceira como parte integrante do mesmo destaca-se pela presença de vegetação típica de áreas salobras associadas a estuários: Zoostera noltii, Ruppia maritima, a vegetação anual na área de sapal baixo e salinas abandonadas com Salicornoia ramosissima, prados de Spartina maritima, matos halófitos de espécies perenes, juncais halófitos e Scirpus maritimus (MARQUes, 2005).

No que respeita à avifauna destacam-se seis espécies de aves que representam cerca de $89 \%$ do total de aves limícolas presentes na Ilha da Morraceira, de-

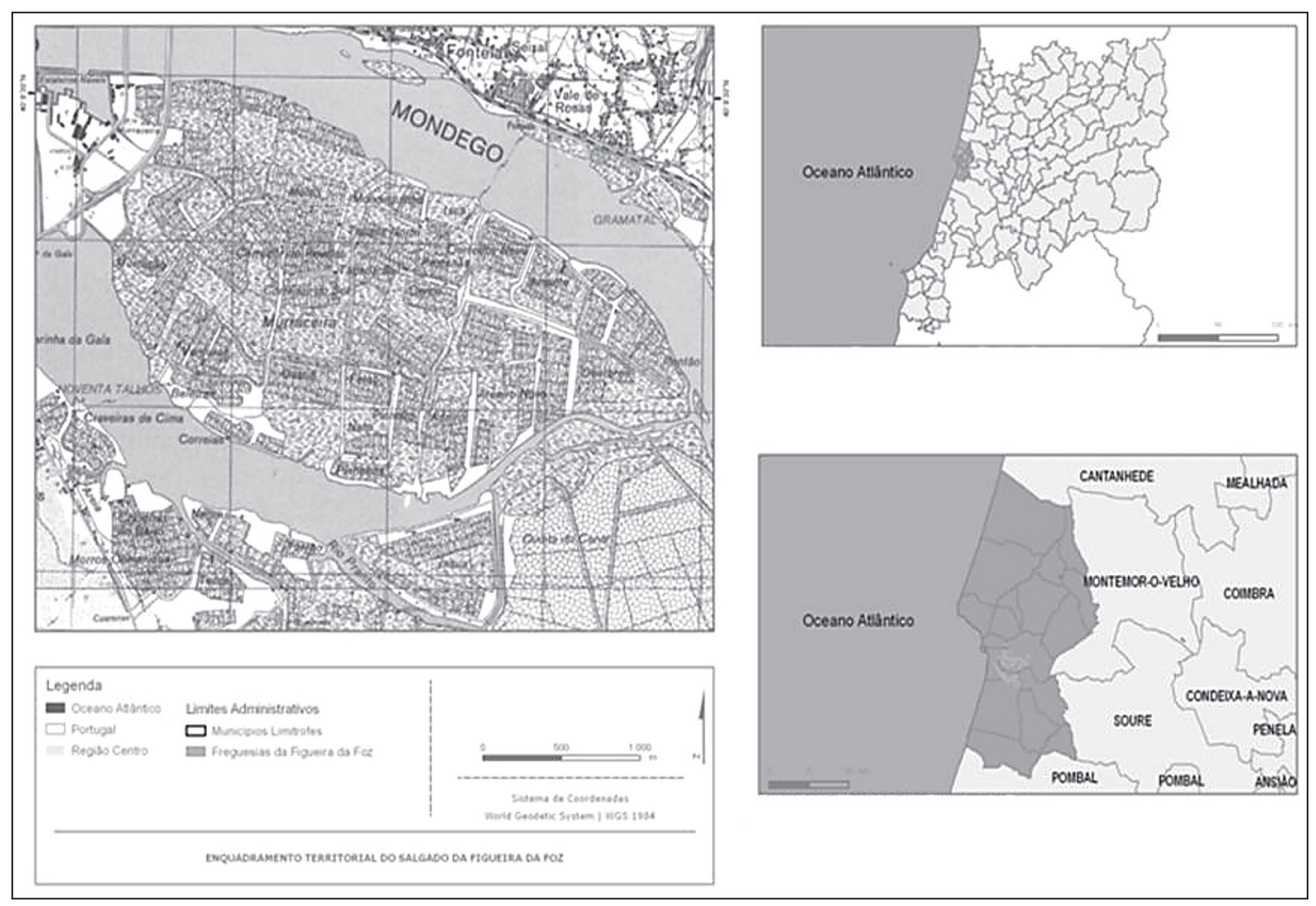

Figura 1

Enquadramento da ilha da Morraceira no contexto municipal e regional Fonte: IGP, CAOP - 2010 e IGeoE, 2000. 
signadamente Pilrito-de-peito-preto (Calidris alpina), Alfaiate (Recuvirostra avosetta), Pernilongo (Himantopus himantopus), Borrelho-de-coleira-interrompida (Charadrius alexandrinus), Tarambola-cinzenta (Pluvialis squatarola) e Borrelho-de-coleira-grande (Charadrius hiaticula). De referir, ainda, que a avifauna da Ilha da Morraceira não se limita apenas à existência de aves limícolas, sendo possível observar uma importante comunidade de outras aves, nomeadamente Tartaranhões dos Pauis (Circus aeroginosus), Chilreta (Sterna albifrons) e Guincho (Larus ribibundus). No período de Inverno é, ainda, de destacar a presença de outras espécies de aves, em particular a Águia pesqueira (Pandion haliaetus) e os Flamingos (Phoenicopterus ruber), ou de um número significativo de patos (Anas).

Já em termos das características económicas e culturais é de destacar o facto da Figueira da Foz se encontrar entre os cinco principais salgados da costa portuguesa (os quais se encontram localizados entre a "Ria" de Aveiro e a Foz do Guadiana), embora deva ser referido que a sua importância económica tem vindo a decair ao longo do último século, muito por força das transformações introduzidas na conservação dos alimentos. Assim, a importância histórica e ambiental do salgado motiva a necessidade de requalificação desta atividade no sentido da sua preservação, promoção e criação de novos caminhos para a utilização do sal, bem como revitalização de todo o salgado, numa perspetiva de manutenção do equilíbrio dos frágeis ecossistemas deste setor do território concelhio.

Associada à necessidade de se pugnar pelo equilíbrio deste ecossistema, outra atividade que deve ser devidamente equacionada é a aquacultura, já que este setor do território apresenta condições ecológicas que permitem às diferentes espécies, alcançar taxas de crescimento bastante satisfatórias e que poderá assumir grande importância em termos de rentabilidade económica. As espécies mais produzidas na ilha são o robalo, a dourada, o sargo, o linguado, a tainha, a enguia, e, recentemente, as ostras e as amêijoas.

Todavia, a produção em aquacultura é também responsável pela perturbação dos frágeis ecossistemas associados à ilha da Morraceira, já que as salinas ativas e inativas se assumem como habitat de inúmeras aves que escolhem este setor do território para nidificar. Assim, e considerando que esta atividade não reúne consenso generalizado entre os diferentes stakeholders, a sua continuidade e promoção deverá ser bastante ponderada e analisada em termos de ampliação das explorações existentes.
A agricultura biológica e a exploração de algas para fins medicinais, embora com fraca representatividade, são exemplos de boas práticas onde a sustentabilidade se encontra patente pela aliança entre a componente biológica, a criação de alternativas para a dinamização do espaço e a constituição de outras atividades económicas, contribuindo, assim, para a dinamização e promoção deste território.

Esta riqueza ambiental, ecológica e patrimonial do salgado estuarino justifica a existência de uma embrionária componente de lazer e turismo associada, que presentemente e restrita ao setor de Armazéns de Lavos, se materializa na existência de duas rotas, nomeadamente a Rota das Salinas (pedestre) e a Rota Fluvial Sal do Mondego, ambas associadas ao Ecomuseu do Sal.

Justificava-se, assim, a implementação de um projeto integrado que mais do que enunciar um conjunto de medidas de conservação, pugnasse pela valorização turística - cultura e património -, mas fundamentalmente, pela valorização dos próprios ecossistemas (Cordeiro, coord, in press- $b$ ).

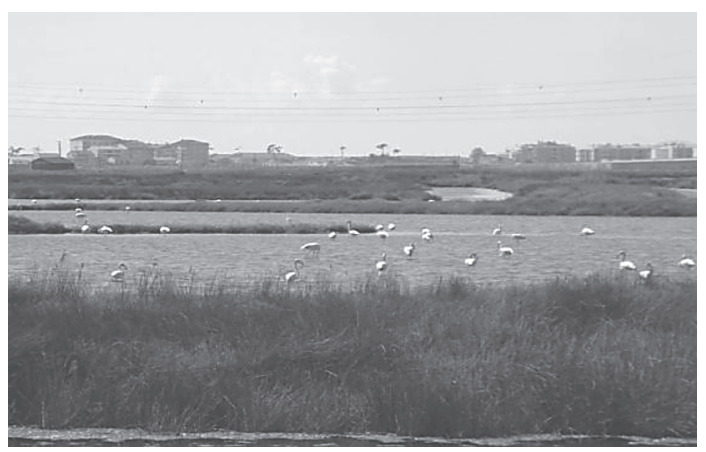

Fotografia 1

Vista geral da ilha da Morraceira

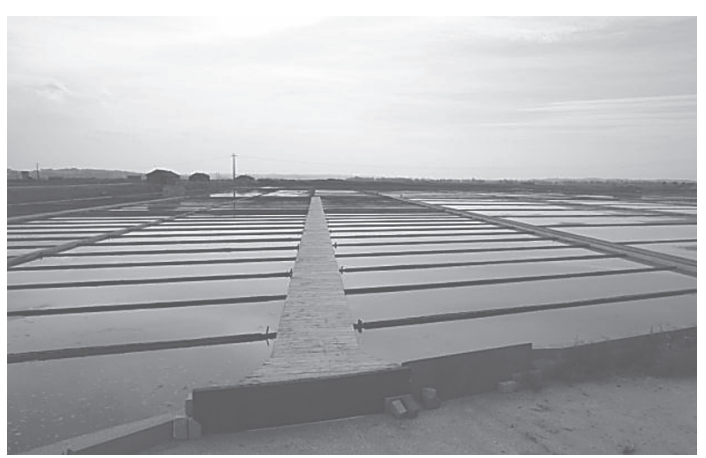

Fotografia 2

Marinha de sal 


\section{Uma Proposta de Intervenção Integrada para o Salgado da Figueira da Foz}

O aproveitamento do potencial endógeno de um setor que tem sido esquecido pela população do próprio município foi a base para o desígnio de desenvolvimento sustentável, não só da ilha da Morraceira, mas do todo do concelho. Este projeto considerou como peças fulcrais a proteção e valorização da biodiversidade, a recuperação e valorização do património tradicional, a potencialização e atração de atividades económicas viáveis e a promoção de atividades turísticas, numa perspetiva de sustentabilidade. Neste sentido, o "Plano de Valorização Turística da Ilha da Morraceira" acabou por se basear em três eixos fundamentais: criação e requalificação de infraestruturas, conceção e desenvolvimento de produtos turísticos e marketing do destino (Figura 2).

O Eixo 1 - Criação e requalificação de infraestruturas - integra as ações consideradas prioritárias que visam a valorização paisagística e a adaptação do local às exigências de um espaço turístico. As medidas adotadas não devem, em circunstância alguma, colocar em causa a preservação da biodiversidade e, por outro lado, devem ter em especial atenção a integração de todas as infraestruturas no contexto ambiental local. Preconizou-se, assim, a criação do Centro de Interpre-
tação/Investigação, cujo objetivo primordial será a dinamização, valorização e interpretação dos valores paisagísticos e patrimoniais da ilha da Morraceira (aqui não só no ambiente do Estuário, mas associada a toda a bacia hidrográfica do Mondego), bem como o apoio científico às atividades desenvolvidas na ilha, no sentido de rentabilizar a produtividade e promover o seu desenvolvimento de um modo sustentado.

Ainda neste contexto, e na lógica do que tem vindo a ser desenvolvido pelo Ecomuseu do Sal, equacionou-se a construção de três novos cais de acostagem que permitam a dinamização de percursos estuarinos que efetuam a ligação entre os diferentes espaços patrimoniais e temas identificados no diagnóstico. Por seu turno, o Núcleo Museológico do Sal deve ser dinamizado de uma forma integrada com o Centro de Interpretação/Investigação, de modo a que todo o setor estuarino se torne um local atrativo, não só para os residentes no próprio concelho, como também para os próprios turistas. Aliás, nesse sentido, a valorização deste espaço deverá passar pela sua integração na Rota "Sal do Atlântico" oferecendo, assim, outras oportunidades de ligação e divulgação a nível europeu do projeto da ilha da Morraceira.

No quadro deste primeiro eixo destaca-se, ainda, a intervenção no "Moinho de Maré das Doze Pedras" (único a nível nacional com doze engenhos), que deve

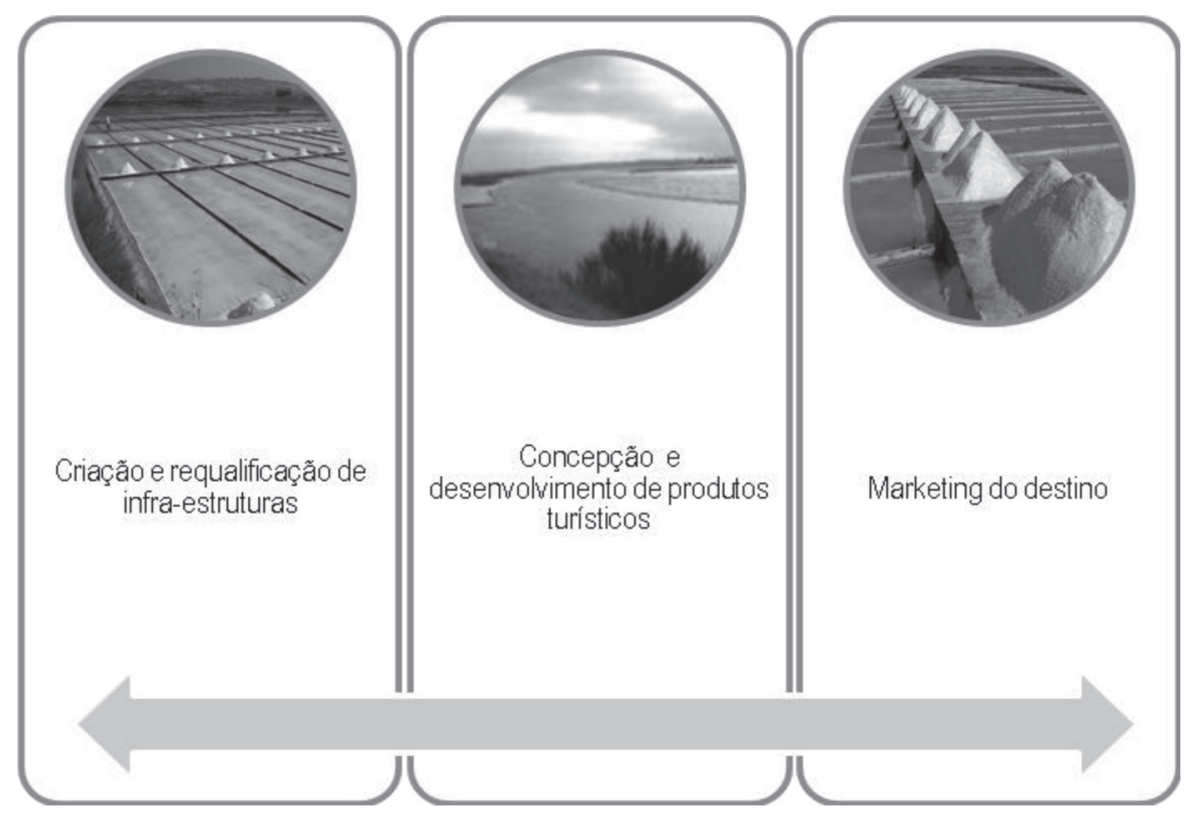

Figura 2

Eixos de desenvolvimento

Fonte: Plano de Valorização Turística da Ilha da Morraceira. Novas Utilizações do Potencial Endógeno do Salgado da Figueira da Foz (CORDEIRO, coord, 2012) 
ser equacionada no projeto mais vasto do estuário do Mondego, no qual, de forma gradual, se pretende atingir uma musealização e respetiva integração em rotas de âmbito municipal, regional e nacional.

O Eixo 2 - Conceção e Desenvolvimento de Produtos Turísticos - visa, no essencial, a criação de novos produtos e a renovação dos já existentes, de modo a cativar o visitante, devendo apostar-se na escolha de produtos icónicos que permitam a consolidação e articulação desta oferta turística. Assim, as intervenções passam pela criação de rotas de ecoturismo, designadamente pedestres, cicláveis e estuarinas, sendo de realçar que uma delas (rota do Braço Norte do Mondego) foi equacionada numa lógica de "Turismo Acessível" passando a Figueira da Foz a apresentar a oferta de um percurso de avifauna adaptado a cidadãos com mobilidade reduzida e para o qual se prevê não só a estabilização do piso, mas também a instalação de um parque de estacionamento para apenas uma ou duas viaturas ligeiras de apoio a esses mesmos cidadãos (Figuras 3 e 4).

Salienta-se o facto de todas estas intervenções terem subjacente a necessidade de uma requalificação/adaptação das infraestruturas de apoio, bem como do património edificado, o que contribuirá para uma clara melhoria do espaço em termos paisagísticos.

Ainda associado ao contributo para fomentar a diversidade da oferta turística, mas também numa lógica de potenciar as atividades económicas que presentemente se encontram em desenvolvimento, de salientar a necessidade de uma rápida concretização da implementação e respetiva certificação da marca "Sal da Figueira". Deste modo, pretende-se, também, direta ou indiretamente, revitalizar esta atividade no contexto da economia local, a par de uma dinamização das restantes atividades económicas existentes na ilha - aquacultura, agricultura biológica e exploração de algas.

A integração dos pontos onde são desenvolvidas estas atividades nas rotas de ecoturismo e a possibilidade de participação dos turistas visitantes contribuirá, por um lado, para a sua divulgação e, por outro, para a sensibilização da população em geral para estas temáticas. Assim, criar-se-ão um conjunto de atividades complementares à visita do Centro de Interpretação/ Investigação, tornando o local atrativo para um público mais diversificado.

Já no que diz respeito ao Eixo 3 - Marketing do Destino - este apresenta como principal objetivo uma eficaz divulgação do local e das respetivas atividades desenvolvidas pelos diferentes meios de comunicação.
Tal passará não só pela criação de uma plataforma web própria, mas também pela integração do destino em sites de divulgação turística e criação de documentos convencionais (panfletos, brochuras e guias de divulgação turística).

Num outro patamar desta intervenção deverão vir a ser promovidos cursos de formação no âmbito do "Projeto Educativo Local", os quais poderão funcionar numa dupla perspetiva: aperfeiçoamento dos conhecimentos sobre as diferentes temáticas que a ilha da Morraceira encerra e divulgação do espaço e das atividades que nele se desenvolvem.

\section{Capacidade de Carga da llha da Morraceira}

As áreas protegidas (ou a proteger) associadas a espaços naturais, tal como é o caso da ilha da Morraceira, são cada vez mais utilizadas como "nicho de mercado" para o fomento de atividades económicas, numa ótica de sustentação do próprio espaço natural, aliado ao benefício das populações da área envolvente. Aqui enquadram-se não só as atividades económicas atuais, como também o desenvolvimento de novas atividades associadas ao lazer.

Porém, não podem ser postas em causa as maisvalias que tornaram este local único em termos regionais e vocacionado para a atividade turística alternativa ao dominante sol/mar - subentenda-se aqui as qualidades paisagísticas e ambientais do espaço. A fruição destes espaços numa lógica de atividade turística deve, assim, ser utilizada para a sensibilização da população para as questões da conservação e preservação da natureza e da sustentabilidade, papel que, por norma, cabe às autoridades locais (autarquia) e às próprias empresas de animação turística, como alguns autores têm vindo a referir (SOUSA e JACINTO, 2008).

É neste contexto, e no âmbito da crescente responsabilidade das autarquias e das próprias empresas no contexto das questões ambientais, que se inicia a aplicação da gestão ambiental ao turismo, sendo fulcral a identificação e quantificação dos impactos desta atividade no meio em que é praticada. Contudo, mais que uma questão ambiental, esta preocupação pode também tornar-se uma extraordinária estratégia de marketing territorial.

É neste sentido que surge o cálculo da capacidade de carga, metodologia utilizada na ótica da adminis tração e planeamento das atividades realizadas em espaços de grande valor natural, cujo objetivo primordial passa pela sustentabilidade do espaço (SEBAStı̃̃o, 2010). 


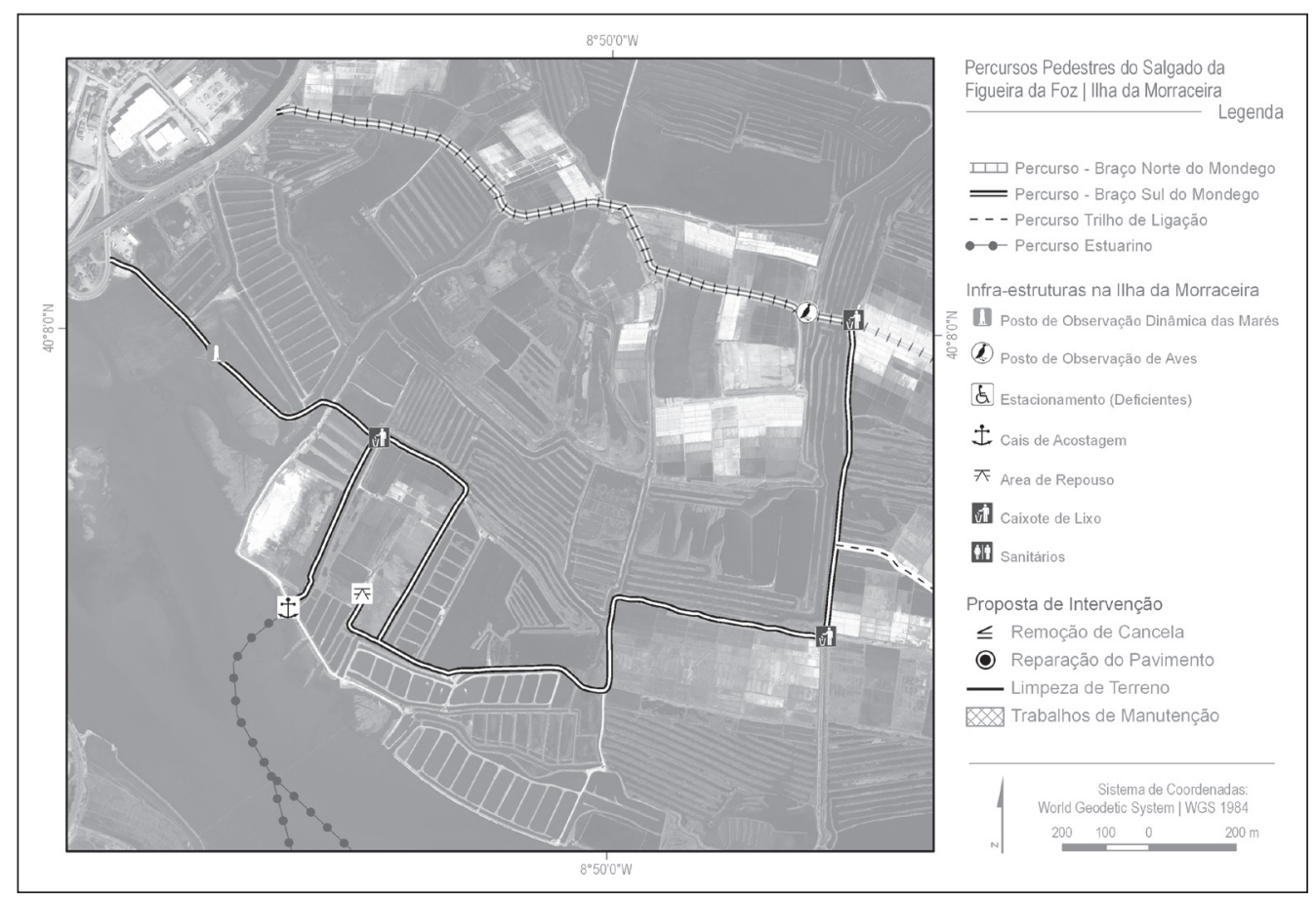

Figura 3

Traçado do PR1 - braço norte do Mondego.

Fonte: Adaptado de Câmara Municipal da Figueira da Foz, 2009.

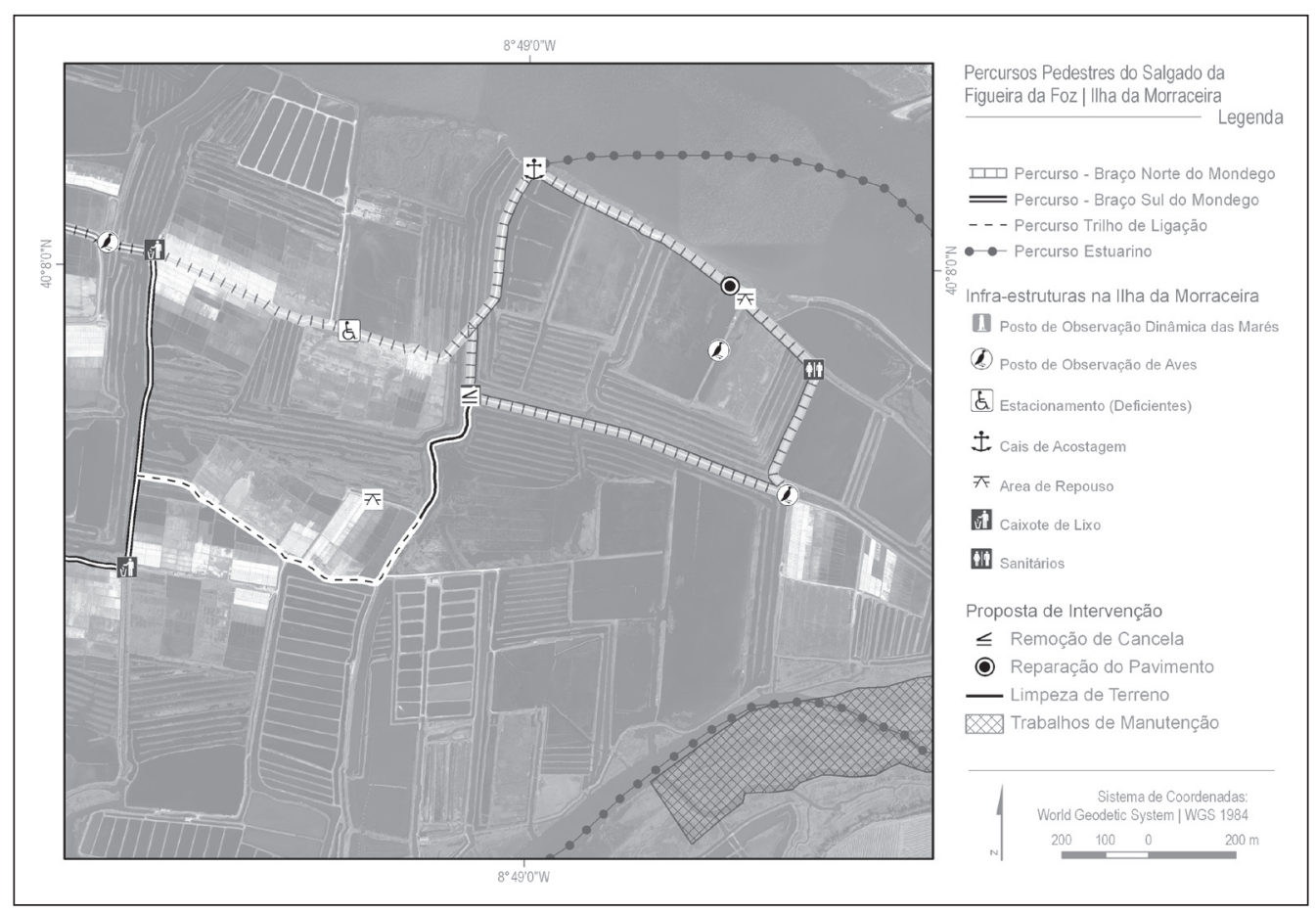

Figura 4

Traçado do PR2 - braço sul do Mondego.

Fonte: Adaptado de Câmara Municipal da Figueira da Foz, 2009. 
Neste contexto, para a ilha da Morraceira foi utilizada a proposta de cálculo apresentada por CIFUENTES (1992), a qual se subdivide em três parâmetros: "a Capacidade de Carga Física (CCF) - que faz o estudo da relação entre o espaço total do local e o espaço necessário por cada pessoa; a Capacidade de Carga Real (CCR) - que estuda os fatores de correção (FC) particulares a cada local, de acordo com as suas características; a Capacidade de Carga Efetiva (CCE) - que vai delimitar a CCR em função da Capacidade de Manejo da área" (Prado, 2005).

De uma forma mais pormenorizada, a "Capacidade de Carga Física" estabelece o limite máximo de visitas diárias numa área, tendo por base o comprimento do(s) percurso(s) pedestre(s), a distância entre os grupos e o período disponível para a visita. Por sua vez, a "Capacidade de Carga Real" consiste no número máximo de visitas diárias, determinado pela "Capacidade de Carga Física" de um percurso pedestre, após a aplicação de um conjunto de fatores de correção, definidos conforme as características do espaço em causa. Os fatores são obtidos através de variáveis físicas, ambientais, biológicas e de administração do espaço, como sejam a acessibilidade, a temperatura, a erosão dos solos, o período de nidificação das aves, entre outros. Neste contexto deve ser referido que quanto maior for o número de fatores de correção, maiores serão as restrições à capacidade de carga do espaço.

Por fim, refere-se a "Capacidade de Carga Efetiva"1 como o número máximo de visitas permitidas por dia. Esta calcula-se tendo por base a comparação entre a "Capacidade de Carga Real" e a "Capacidade de Administração", que corresponde ao somatório das condições necessárias à administração do espaço a fim de desenvolver as atividades e alcançar os objetivos para o qual foi criado.

Partindo desta metodologia procedeu-se, então, ao cálculo da capacidade de carga de cada um dos percursos destinados à prática do pedestrianismo projetados para as rotas de ecoturismo (CoRDEIRo et al., in press).

Com base nas respetivas características dos percursos PR1 - Braço Norte do Mondego e PR2 - Braço Sul do Mondego (Quadros 1 e 2) tornou-se possível calcular que a capacidade de carga diária do Percurso Norte do Mondego é de cerca de 130 visitas, enquanto que a do percurso do Braço Sul do Mondego roda as cerca de 360

${ }^{1}$ Uma vez que o projeto ainda não se encontra em atividade, não se torna adequado calcular a Capacidade de Carga Efetiva, na medida em que envolve um conjunto de variáveis relacionadas com a administração do espaço. Porém, tal deve ser providenciado numa fase posterior, seguindo o modelo acima descrito. visitas. Pode assim constatar-se que os dois percursos apresentam uma capacidade de carga que ronda as 490 visitas diárias.

No entanto, não pode deixar de ser referido que aos valores encontrados deve ser associado o peso da permanência dos trabalhadores ligados à salicultura e aquacultura (maioritariamente entre Maio e Outubro) e também o número de visitantes oriundos das rotas estuarinas, os quais podem vir a induzir perturbações acrescidas nos ecossistemas da ilha. Neste sentido, os valores associados aos cálculos da capacidade de carga devem ser revistos, especialmente após a implementação do Centro de Interpretação/Investigação da ilha da Morraceira.

\section{Algumas Notas Conclusivas}

O potenciar, em termos económicos, de um setor natural do concelho da Figueira da Foz, foi assumido como um dos principais desafios de uma nova estratégia de turismo sustentável, entendida como complementar ao sazonal turismo sol/mar.

Com base no diagnóstico efetuado, procedeu-se à caracterização da ilha da Morraceira, destacando as suas ofertas, os seus principais problemas e recursos endógenos, tornando possível o equacionar de um plano de desenvolvimento onde o conceito de sustentabilidade é uma peça fulcral.

A ilha da Morraceira, localizada no estuário do Mondego, apresenta-se, desde há muito, como um espaço esquecido pela população local, constatando-se que, no presente momento, desperdiça-se uma "jóia" que deveria ter sido equacionada, desde há muito, como estratégica na promoção do próprio concelho (CORDEIRO et col., in press-b).

A sua riqueza natural - área de predomínio do sapal com um ecossistema particularmente rico e único na região, associado em particular à avifauna RAMSAR e a forte componente cultural, associada à longa história da prática da salicultura, assumem-se como potencialidades que devem ser consideradas como ponto de partida para a reabilitação e reafirmação deste espaço na economia e desenvolvimento local.

Assim, e partindo da filosofia inerente ao projeto desenvolvido para a Figueira da Foz, designadamente o que diz respeito à necessidade de coesão e complementaridade entre os eixos definidos para o setor do turismo, pretende-se que a ilha da Morraceira se afirme como um espaço turístico que funcione de forma complementar ao turismo sol/mar (atual imagem de marca 
Quadro I

Cálculo da capacidade de carga do PR1 - braço norte do Mondego

\begin{tabular}{|c|c|}
\hline \multicolumn{2}{|c|}{ Rota PR1 - Braço Norte do Mondego } \\
\hline Caraterísticas & Percurso circular de pequena rota \\
\hline Dias disponiveis para visita & Segunda a Domingo \\
\hline Espaço por pessoa & $1 \mathrm{~m}^{2}$ (convencional) \\
\hline$N^{\circ}$ limite de pessoas por grupo & 10 pessoas \\
\hline Tempo necessário para percorrer o percurso & $2,45 \mathrm{~h}$ \\
\hline Tempo para a visita diária & 8 horas \\
\hline Extensão do percurso & $7,83 \mathrm{~km}$ \\
\hline Largura média & $2 \mathrm{~m}$ \\
\hline Distância mínima entre grupos & 50 m (CIFUENTES, 1992) \\
\hline Visitas diárias ao percurso/pessoa & 3,27 visitas \\
\hline \multicolumn{2}{|c|}{$\mathrm{CCR}=\mathrm{CCF} \times \underline{100-\mathrm{FC}_{\underline{t}}} \times 100-\mathrm{FC}_{n}=250,482 \times \underline{100-23,051} \times 100-33,3=129,22$} \\
\hline 100 & 100 \\
\hline
\end{tabular}

Quadro II

Cálculo da capacidade de carga do PR2 - braço sul do Mondego

\begin{tabular}{|c|c|}
\hline \multicolumn{2}{|c|}{ Rota PR2 - Braço Sul do Mondego } \\
\hline Caraterísticas & Percurso linear de pequena rota \\
\hline Dias disponíveis para visita & Segunda a Domingo \\
\hline Espaço por pessoa & $1 \mathrm{~m}^{2}$ (convencional) \\
\hline $\mathrm{N}^{\circ}$ limite de pessoas por grupo & 10 pessoas \\
\hline Tempo necessário para percorrer o percurso & $1,45 \mathrm{~h}$ \\
\hline Tempo para a visita diária & 8 horas \\
\hline Extensão do percurso & $4,75 \mathrm{~km}$ \\
\hline Largura média & $2 \mathrm{~m}$ \\
\hline Distância mínima entre grupos & 50 m (CIFUentes, 1992) \\
\hline Visitas diárias ao percurso/pessoa & 5,52 visitas \\
\hline \multicolumn{2}{|c|}{$\mathrm{CCR}=\mathrm{CCF} \times \underline{100-F C_{t}} \times \underline{100-\mathrm{FC}_{n}}=697,176 \times \underline{100-23,051} \times \underline{100-33,3}=359,67$} \\
\hline 100 & 100 \\
\hline
\end{tabular}

da Figueira da Foz), sempre numa lógica de sustentabilidade e associada aos restantes sítios RAMSAR do Baixo Mondego.

Para tal, torna-se fulcral a dinamização e reestruturação das atividades que têm vindo a ser desenvolvidas, destacando-se, em especial, a salicultura, mas também a aquacultura e a agricultura biológica, integrando-as com as novas funções, num espaço que se deseja associado ao ecoturismo. Deste modo, prevê-se a concretização de um projeto sob a lógica de três eixos estratégicos que passam pela criação e requalificação de infraestruturas, a conceção e desenvolvimento de produtos turísticos e o marketing do destino.

O objetivo final deverá ser a criação de um espaço de recuperação, conservação e divulgação do património natural e cultural, que viabilize a diversificação da oferta turística no concelho e contribua para um desenvolvimento sustentável do território. 0 projeto será, assim, concertado com o ecossistema da ilha da Morraceira, não devendo colocar em causa o seu equilíbrio. Para tal tornou-se fundamental perspetivar a capacidade de carga do espaço numa lógica de planeamento e gestão da própria oferta e nas decisões estra- tégicas para a viabilidade e durabilidade de um espaço turístico sob a égide da sustentabilidade.

\section{Bibliografia}

Cifuentes, M. A. (1992) - Determinación de la capacidad de carga turística en áreas protegidas. Centro Agronómico Tropical de Investigación y Enseñanza (CATIE). Turrialba, Costa Rica, pp. 22.

Cordeiro, A. M. Rochette (Coord.) (2012) - "Plano de valorização turística da Itha da Morraceira. Novas utilizações do potencial endógeno do estuário da Figueira Da Foz", Município da Figueira da Foz. Faculdade de Letras da Universidade de Coimbra, Figueira da Foz, pp. 84.

Cordeiro, A. M. Rochette; Paredes, Liliana C. e Alves, Carolina D. (in press) - A llha da Morraceira (Figueira da Foz) como potenciadora de turismo sustentável - uma proposta de intervenção integrada. Actas da Conferência Nacional sobre Sustentabilidade no Turismo. Associação Portuguesa de Engenharia do Ambiente - APEA. Évora.

Cordelro, A. M. Rochette (Coord.) (in press-a) - "Plano de desenvolvimento dos desportos náuticos e aventura", in 
Atlas Desportivo Municipal do Município da Figueira da Foz. Faculdade de Letras da Universidade de Coimbra, Figueira da Foz, pp. 160.

Marques, J. C. (2005) - Proposta de Plano Director para a llha da Morraceira. Relatório final (Coord.). Universidade de Coimbra (policopiado), pp. 102.

Paredes, L. C. (2008) - Ecoturismo: um turismo alternativo para o Baixo Mondego. Dissertação de Mestrado, Faculdade de Letras da Universidade de Coimbra, pp. 161.

Prado, M. (2005) - Ecoturismo e capacidade de carga das trilhas da Fazenda Mundo Novo/Candindé do São Francisco/SE Universidade Federal de Sergipe.

SEBAstIão, I. (2010) - Aplicação da pegada ecológica ao turismo. Como a pegada ecológica pode influenciar a gestão ambiental. Lisboa, Universidade Nova de Lisboa, pp. 184.

SousA, C. e JaCinTo, P. (2008) - Desportos de natureza: impactes ambientais e sua minimização. Castelo Branco: Escola Superior Agrária de Castelo Branco, pp. 1-12.

RibeIRo, J. L. (2005) - "Factores ambientais e impactes antrópicos condicionantes das actividades tradicionais no Estuário do Mondego". I Seminário Internacional sobre o Sal Português. Instituto de História Moderna da Universidade do Porto, pp. 395 - 405.

RibeiRo, J. L. (2006) - Centralidade geo-ambiental do estuário do Mondego no ordenamento da zona costeira da Figueira da Foz. Tese de doutoramento apresentada à Faculdade de Letras da Universidade de Coimbra, pp. 376. 